\title{
AUTONOMÍA PERSONAL, DERECHOS HUMANOS Y DEMOCRACIA: ¿¿UN TRIÁNGULO DEMASIADO FELIZ?
}

\author{
José Luis Colomer \\ Universidad Autónoma de Madrid
}

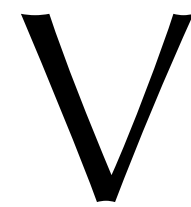

uelvo a leer trabajos de Francisco LAPORTA y Liborio HIERRO con gran provecho y placer, y también con algo de melancolía. Y constato que los acuerdos intelectuales entre ambos van más allá de lo que pensaba. Una de esas coincidencias la encontramos en el papel primordial que ambos autores dan en sus teorías filosófico-jurídicas al valor de autonomía personal, al que LAPORTA presenta como fundamento de su admirable teoría del imperio de la ley y HIERRO convierte en fundamento único de su ambicioso y meritorio sistema de los derechos humanos, y de toda su teoría de la justicia.

A mi parecer, nuestros dos protagonistas son en exceso entusiastas sobre las virtudes teóricas del valor de autonomía personal. LAPORTA sostiene que «todo el complejo mundo de normas e instituciones que constituyen el imperio de la ley no es otra cosa que una apuesta moral implícita en favor de la autonomía personal» (2007: 18). Y Liborio HIERRO va aún más lejos cuando, tras proponer que se consideren como «derechos humanos» aquellos «que son condición necesaria para que una persona [...] pueda desenvolverse como agente moral en un contexto dado», afirma que «solo asumiendo que el primer valor moral se sitúa en la autonomía del individuo [...] los derechos humanos tienen un carácter fundamental (o legitimador) y ofrecen una respuesta teórica a los tres grandes problemas teóricos de la justicia: por qué es justo ordenar (la justicia como legalidad), quién está justificado para ordenar (la justicia como legitimidad en origen) y qué es lo que está justificado ordenar (la justicia como legitimidad en contenido)». Y especifica inmediatamente: «Los derechos humanos ofrecen una respuesta completa porque en base a un mismo principio resuelven las tres cuestiones: las normas son legítimas porque son necesarias para el desarrollo de la autonomía individual, la competencia normativa es legítima si y solo si deriva del ejercicio de la autonomía por los destinatarios [...] y las normas son justas si y solo si tienen como contenido la protección y la promoción de esa misma autonomía» (HIERRO, 2002: 39 40; 2014: 50; 2016: 55, 131).

En este comentario voy a detenerme en tres aspectos de sus propuestas: el propio concepto de autonomía que ambos autores manejan, el valor literalmente «fundamental» que le otorgan y el vínculo inmediato que establecen entre autonomía personal y teoría política democrática. Y debo decir que lo hago con cierta incomodidad ante la ligereza o injusticia que supone objetar en menos de tres mil palabras a propuestas 
filosóficas que demuestran la capacidad y seriedad intelectual excepcionales de sus autores.

\section{AUTONOMÍA PERSONAL Y AGENCIA MORAL}

Desde mi punto de vista, HIERRO y LAPORTA manejan un concepto de autonomía personal excesivamente amplio, en el que se juntan elementos de ideas diferentes y de muy distinto alcance, como la idea de agencia moral, o la idea kantiana de autonomía o libertad de la voluntad racional y el valor o principio liberal de autonomía personal. Aunque doy por supuesto que ninguno de ellos intenta presentar una concepción detenida de la idea de autonomía, y que estamos ante una idea particularmente compleja y polifacética ${ }^{1}$, pienso que ambos se apresuran en su uso con resultados que no añaden claridad a las tesis que defienden. Más en concreto, no me parece acertado confundir o identificar la idea («kantiana») de la voluntad libre o «autónoma» en tanto no determinada por «fuerzas» o impulsos, deseos o intereses y, por tanto, como capacidad para actuar por razones, esto es, por principios morales «universales» — que nos convertiría en «agentes morales»— con el principio de la moral política que exige respetar la independencia del juicio de cada individuo en el gobierno de la propia vida y prescribe no obstaculizar las elecciones del propio individuo, e incluso facilitar a este conjuntos de opciones valiosas para dichas elecciones.

Es cierto que entre ambas ideas hay elementos comunes pero también que tienen diferentes sentidos, alcance, y orígenes doctrinales. La primera se afirma de los seres humanos en general (con excepciones) y es, como bien insisten nuestros autores, condición de posibilidad de la idea de responsabilidad, e incluso de las de norma, imperativo, e incluso de la de «obligación basada en la fuerza» (LAPORTA, 2007: 18-21). O, como ambos autores reiteran, condición de la consideración del ser humano como «agente moral», o también «prerrequisito del discurso moral» (HIERRO, 2002: 42-43; 2016: 55, 131). Pero nada de esto parece propio del valor de autonomía personal como el valor moral y político que se da, en algunas concepciones o teorías morales, al control de la propia vida, esto es, a la libre elección, no obstaculizada por otros, de pautas de acción, planes de vida o concepciones del bien (RAZ, 1986: 369; NINO, 1989: 204). En este caso estamos ante un valor o principio de justicia que, lejos de ser condición de la acción o del discurso moral, es apreciado más o menos en distintas concepciones morales y políticas y cuya realización depende, en gran medida, de condiciones legales, políticas y sociales favorables.

\section{LA AUTONOMÍA PERSONAL COMO «FUNDAMENTO» DE LOS DERECHOS HUMANOS Y DEL IMPERIO DE LA LEY}

Es al segundo concepto, el del valor moral y político del libre gobierno de la propia vida (y no a la idea metafísica de la libertad de la voluntad racional) al que cabe proponer, con nuestros autores, como fundamento último o primordial de los derechos hu-

1 Vid., entre otros, L. Haworth, 1986; J. RAZ, 1983; G. Dworkin, 1988; C. S. NinO, 1989. 
manos, de la teoría de la justicia en general o de «las normas e instituciones del imperio de la ley». Pero pienso que una cosa es defender que dicho valor tenga un alto rango o importancia política, y otra convertirlo en fundamento y criterio único y suficiente de los derechos humanos en general, y de las teorías de la de legalidad, justicia y legitimidad democrática (HIERRO), o en la primordial justificación subyacente al imperio de la ley (LAPORTA).

La capacidad y vocación por la ordenación sistemática que Liborio HIERRO muestra en su obra, le conducen a esbozar «teorías generales» de algunos conceptos y principios básicos de la filosofía del derecho ${ }^{2}$; en este caso, a ofrecer «una respuesta completa a los tres grandes problemas teóricos de la justicia». El principio de autonomía de la voluntad constituiría el fundamento «completo», necesario y suficiente, de esa respuesta a través de la teoría de los derechos humanos. Los tres pilares básicos de esta comparten el mismo fundamento: «El derecho a la seguridad jurídica es una necesidad básica derivada de la autonomía», «todo ser humano tiene derechos a las libertades necesarias para desenvolverse como agente moral» $\mathrm{y}$ «el respeto a la autonomía moral [o personal] nos obliga a adoptar un principio de igualdad de oportunidades» (2016: 160, 165-166).

No creo, sin embargo, que ese intento de sistema pueda culminarse con éxito. De hecho, no termino de ver, en este caso, sus ventajas reales, teóricas o prácticas. Pues una teoría de la justicia, o una filosofía política, de tipo monista —esto es, que hace derivar todos los principios o valores de la moral política de un único fundamento o valor último, como en este caso el de autonomía - debería tener, frente a sus alternativas pluralistas, dos virtudes teóricas principales: el valor o principio último proporcionaría la justificación de los demás principios o valores, y además serviría como parámetro para resolver los conflictos entre los principios o valores «derivados». Pero, desde mi punto de vista, ninguna de esas ventajas se obtiene en este caso.

De un lado, no me parece verosímil sostener que los diversos intereses, necesidades o valores que subyacen a los distintos derechos humanos puedan ser explicados como derivados o dependientes de su contribución al valor de autonomía personal, o que concebirlos como medios para la autonomía personal o exigencias de esta contribuya a una mejor comprensión de su significado, contenido o importancia. No quiero decir que no exista relación entre autonomía y, por ejemplo, seguridad, igualdad o bienestar (el caso del valor y los derechos de libertad es, obviamente distinto), o que la presencia o ausencia de estos no incida en la autonomía de las personas. Pero está lejos de ser claro que aquel sea su único o principal valor o que no tengan un valor independiente o intrínseco, es decir, que no constituyan por sí mismos «necesidades», «intereses básicos» o valores de la vida personal o de una sociedad justa que justifiquen suficientemente su consideración como fundamentos de derechos humanos. Por eso cabe pensar en tensiones o conflictos entre los valores de seguridad, igualdad o bienestar y el de autonomía personal, y la consiguiente necesidad de ponderar entre ellos en ciertos casos, lo que no tendría sentido si los primeros derivasen su valor solo a partir del segundo.

2 Este rasgo lo comparte HIERRO con su admirado Norberto BOBBIO, que, sin embargo, fue precisamente aquí mucho más descreído o prudente, al descartar, creo que con acierto, que pudiera formularse un fundamento único para los derechos humanos. 
En segundo lugar, no veo que el principio de autonomía cumpla o pueda cumplir el papel de principio o valor superior desde el que se resuelvan las contradicciones o conflictos entre derechos, como ocurriría si aquel fuera el fundamento y criterio último de los derechos humanos. No se me ocurre cómo se apelaría a esa instancia superior en muchos conflictos usuales entre derechos humanos o fundamentales, como los que se suscitan entre, por ejemplo, los derechos a la libertad de expresión y la intimidad, o entre el derecho a la igualdad como no discriminación y la libertad de asociación, o entre el derecho a la intimidad y el derecho o valor de la seguridad personal o pública, o entre algunos derechos de libertad e importantes derechos sociales o económicos, o tantos otros. En todos estos casos, el principio de autonomía personal podría servir como un argumento más en un sentido u otro, pero no parece que como criterio o principio superior dé la solución en su supuesta calidad de fundamento moral de los derechos.

Tampoco la gran apuesta teórica de Francisco LAPORTA de hacer de la autonomía personal el fundamento primordial del conjunto de «normas e instituciones que constituyen el imperio de la ley» me parece suficientemente convincente, al menos con el alcance que su autor quiere darle.

El núcleo del argumento de LAPORTA sostiene que «un componente esencial de la autonomía personal es que las personas puedan trazar y seguir proyectos o planes de vida, que unifican y dan sentido a esas vidas a la largo del tiempo, y permiten hablar de "control" por uno mismo de su vida y sus proyectos» (2007: 32). Esto requiere que las consecuencias de nuestras acciones sean predecibles, lo que solo es posible si, en lo que al control de conductas por el derecho se refiere, el sistema jurídico se configura según el denominado «modelo de las reglas».

Ahora bien, y aunque, una vez más, la brevedad y ligereza de mi comentario no hace justicia a la riqueza del trabajo de LAPORTA, creo que la conexión no deja de ser un tanto forzada y a costa de unir dimensiones o medidas de la previsibilidad que el propio LAPORTA reconoce como diferentes. Y es que hay una distancia importante entre la necesidad de regularidades de conductas, y así de normas y reglas, y sistemas normativos sociales y jurídicos, que nos permitan albergar expectativas razonables de comportamiento mutuo, y la de la decisiones judiciales uniformes que posibilitaría el modelo positivista de aplicación de reglas como razones excluyentes. Y también hay una diferencia importante entre la exigencia de la autonomía personal de poder trazar planes y proyectos de vida generales [como «crear una familia estable o realizar una vocación profesional» (2007: 33)] y la planificación minuciosa de nuestro futuro que impliquen el cálculo preciso de consecuencias de acciones y, por tanto, de escenarios sociales muy definidos y precisos a medio y largo plazo. Y me parece que LAPORTA da un salto argumental excesivo al pasar de aquella condición de la autonomía personal (los planes de vida en sentido rawlsiano) a la exigencia más estricta de predecibilidad que justificaría excluir del derecho cualquier patrón de decisión judicial que no sea el del modelo estricto de las reglas.

Por descontado que no pretendo entrar aquí en la discusión de fondo entre las concepciones del derecho conforme al «modelo de reglas»y sus oponentes «principialistas» o «neoconstitucionalistas». Intento solo apuntar que, desde mi punto de vista, los mejores argumentos normativos o políticos en favor del primero son otros 
distintos al de autonomía personal, como el propio LAPORTA muestra cuando se ocupa del propio valor de la previsibilidad de los efectos de nuestras acciones, de la seguridad jurídica, de la satisfacción de preferencias o de la distribución del poder y la legitimidad democrática.

\section{AUTONOMÍA PERSONAL Y DEMOCRACIA}

Aunque soy, de nuevo, consciente de la ligereza en que incurro al meterme en pocas líneas en cuestiones de mucho calado y especialmente complejas, apuntaré un tercer desacuerdo con las esperanzas que LAPORTA y HIERRO depositan en el valor de autonomía personal, en este caso en lo que se refiere a la tesis que la convierte en fundamento de la democracia. Liborio HIERRO es, de nuevo, categórico en su réplica a Isaiah BERLIN: la «libertad positiva», como decisión democrática en «ámbitos en que las decisiones son interdependientes», no es algo distinto a la autonomía individual ( $y$, por tanto, a la «libertad negativa en la vida personal»), sino que cuando, en vez de atribuir la decisión a una autoridad o al azar «decidimos por mayoría, entonces hemos permitido el mayor ejercicio posible de la autonomía individual [...] en esa situación de interdependencia». Así, «la libertad positiva no es, por tanto, otra cosa que el ejercicio de la autonomía personal en condiciones de interdependencia» (2016: 163-164). Y, para LAPORTA, «el mismo fundamento, la autonomía personal», que exige que la convivencia sea guiada por «pautas con la estructura de reglas», da también respuesta a la pregunta sobre «quién debe producir» esas reglas: «El acuerdo entre agentes autónomos» (2007: 146 y 147). Pero con esa tesis compartida ocurre, en mi opinión, lo mismo que en el punto anterior: que el valor o la utilidad de la idea de autonomía personal como fundamento o principio básico de la teoría de la democracia es escaso o muy limitado, y que más bien son otros los principios o valores básicos de la moral política que pueden desempeñar ese papel.

Es cierto que hablamos inteligiblemente de «autogobierno» o «autonomía» colectiva, y que las instituciones que canalizan las opciones o preferencias de las mayorías nos permiten hablar con sentido del «consentimiento» de los ciudadanos a la autoridad o a la ley, porque el voto implica elección o expresión de las propias preferencias por cada ciudadano. Pero la diferencia entre los dos ámbitos —el de la autonomía individual y la colectiva - es tan importante que, a mi entender, distancia o separa las cuestiones teóricas de una y otra, hasta el punto de que no solo no existe la «conexión necesaria» entre ellas que HIERRo busca, sino que no veo el papel de «fundamentación» que la primera pueda desempeñar en la segunda.

Pensemos en algunas de las cuestiones centrales en la teoría de la democracia —como el «ámbito» de esta, o el nivel o extensión de los grupos que han de constituir las unidades de decisión, o las relaciones entre mayorías y minorías, o el valor que deba darse al pluralismo étnico, religioso, geográfico o social, o los límites a la decisión democrática, esto es, al alcance o poder de las decisiones colectivas frente a los derechos o intereses de los individuos-; o examinemos las discusiones entre quienes defienden versiones distintas de la democracia, como la democracia directa o plebiscitaria frente a la representativa o electiva, o los que proponen formas de democracia deliberativa, 
participativa, elitista, populista, etc. No llego realmente a ver cómo los contenidos y dimensiones de la idea de autonomía personal puedan servir para contestar a aquellas preguntas o argumentar satisfactoriamente en esas discusiones; salvo, tal vez, para plantear objeciones muy serias a las formas de democracia indirecta o electiva, que presumo es la que los propios HIERRO y LAPORTA consideran preferible.

Me parece que para esos empeños teóricos es más interesante o prometedor acudir a valores de la moral política como la igualdad de consideración y respeto, la igualdad de poder o de influencia en las elecciones colectivas o en las decisiones y asuntos públicos, o la igualdad en la expresión y peso de los propios valores, elecciones o preferencias en lo que afecta a todos o configura el marco social compartido. $\mathrm{O}$ a valores como el respeto al pluralismo y a las minorías de diversa índole, la promoción del bien común o de los intereses generales, o la maximización de la satisfacción de preferencias, entre otros.

Es cierto que la propuesta de nuestros autores conduce a una teoría más sistemática de la moral política, y que podría ser ventajosa en su fuerza motivadora en favor de los sistemas democráticos de gobierno, pero no me parece satisfactoria teóricamente o desde las exigencias de la precisión y el rigor analítico que LAPORTA y HIERRO valoran y que tan sobradamente han demostrado a lo largo de su obra.

\section{OBRAS CITADAS}

DwORKIN, G., 1988: The Theory and Practice of Autonomy, CUP.

HaWORTH, L., 1986: Autonomy, Yale UP.

HIERRO, L., 2002: «El concepto de justicia y la teoría de los derechos», en E. Díaz y J. L. ColoMER, Estado, justicia, derechos, Madrid: Alianza Editorial.

- 2016: Los derechos humanos. Una concepción de la justicia, Madrid: Marcial Pons.

LAPORTA, F., 2007: El imperio de la ley, Madrid: Trotta.

NiNO, C. S., 1989: Ética y derechos humanos, Barcelona: Ariel.

RAz, J., 1983: The Morality of Freedom, Oxford: Clarendon Press. 